\title{
Assessment of Insurance Company's Roles in Ethiopian Construction Industries
}

\author{
Abebe Demissew Gashahun \\ School of Civil and Water Resources Engineering, Debre Markos Institute of Technology, Debre Markos \\ University, Debre Markos 251, Ethiopia \\ and P.O.Box: 269
}

\begin{abstract}
Presently, Ethiopia has relatively an extensive program of infrastructure development and it is growing faster. The construction of new infrastructures, high rising buildings, energy and water work projects, airfields etc. are among the major construction activities. Construction insurance plays an increasingly important role in guaranteeing the success of projects. However, insurance sometimes does not receive the attention for it. Construction risks are uncertain events or conditions that may have an adverse effect on the construction projects. Due to this, this research amid to assesses the insurance practice, the problems and challenges encountered while implementing in Ethiopian construction industries. Questioners were designed and both cense and judgmental sampling techniques were applied. The study finds out most of the contractors are willing to buy insurances for their vehicles and plants and has no awareness about other types of construction insurances like third party and contractor's all risk insurance coverage. On the other hand, insufficient documentation and low level of awareness of customers towards the benefit of insurance, financial and professional shortages are challenges that insurance companies faced. As a result, Ethiopian government should create awareness about insurance and formulate enforcing law that enables using of insurances for all construction works.
\end{abstract}

Keywords: - construction, contractors, insurance, risk, role

DOI: $10.7176 / \mathrm{CER} / 12-3-03$

Publication date:March $31^{\text {st }} 2020$

\section{Introduction}

The construction industry is a vital sector of economy in any countries of the world. But it is considered to a highest degree in developing countries around the globe. In Ethiopia the construction industry is one of the tools for the development of the country and it is a booming industry. The industry has grown substantially in the last ten to fifteen years. The construction industry is a risky business due to the unique characteristics of construction projects which can attributed to the fact that construction projects involves many stakeholders, is subjected to external environment impacts like weather conditions, it involves a large amount of capital, different site conditions for different projects, is time and quality sensitive, and also different complex problems (Heidenhain, 2011).

Insurance companies can be used as a risk transfer mechanism by which the construction stakeholders can exchange their uncertainty for certainty. The uncertainty experienced would include whether a loss will occur, when it will take place and how severe will it be (Ashy B, 2014). This uncertainty makes it very difficult to budget and so the stake holders of the construction industry seek ways of controlling the financial effect of the risk. Insurance offers the opportunity to exchange this uncertain loss for a certain loss: the insurance premium. The contractor agrees to pay a fixed premium and in return the insurance company agrees to meet any losses which fall within the terms of the policy (Hicksone, 1987).

In the construction industry, risk is defined as the presence of potential actual threats or opportunities that influence the objectives of a project planning, construction commissioning, and those objectives are in the form of cost schedule, and quality (Abebe D, 2007). Risk is also defined as the exposure to the chance of occurrences of events adversely or favorably affecting project objectives as a consequence of uncertainty (Randell EG, 2003). Is the failure to meet these targets (Dereje, 2014). Is the possibility of loss, damage or any other undesirable events (FIDIC, 2009)? Is lack of predictability about problem structure, outcomes or consequences in a decision or planning situation (Rahman MM, 2002). Is the effect of uncertainty on objectives (Palemer WJ, 1996)?

Generalizing the above ideas of risk, it can be defined as the chance or probability of occurrence of events that could lead to positive (opportunities) or negative (threats) outcome where measurement is very difficult. There are many parties involved in the construction industry, including clients, consultants, contractors, subcontractors, insurers, and suppliers. All parties involved in the construction industry must confront risk in one guise or another; some risks will be peculiar to one party and some shared with other parties.

The clients of the industry ultimately pay the bill and it is important to understand their needs and expectations. From clients' perspective, the risk management process should start from briefing of project to the handover to users. Clients are the first party to conduct the risk management process and involve contractors during the construction stage or at an earlier stage (EPPA, 2011).

Inevitably, all contracts involve risk. Apart from mobilising the managerial and technical expertise and the 
entrepreneurial drive of the contractor, the main reason for a client employing a contractor is simply to pass on the risk to someone else. The reward for carrying the risk is the profit which the contractor will expect over and above the estimated costs plus a reasonable commercial return. The higher the risk, the higher will be the profit that will be needed and expected. Contractors have the major responsibility to deal with construction risks (Hicksone, 1987) (FIDIC, 2009).

Risks which the contractor will have to consider, allocate, assume or lay off can arise at all stages from bid agreement through to construction and any follow up maintenance contract [Hickson, R. J. 1987].

\subsection{Statement of the problem}

The construction industry is a high risk business by itself. So what insurance companies do is share some of that risk by charging some amount of money in form of premium payment. However, in Ethiopia the role of insurance companies in the construction industry is not always clear as why construction insurance exists and how it operates from the perspective of the construction industry (Melesse, 2006).

Construction insurance is a practice of exchanging a contingent claim for a fixed payment to protect the interests of parties involved in a construction project (Ashy B, 2014) (Hicksone, 1987). Construction insurance is a major method of managing risks in the construction industry (EPPA, 2011) (FIDIC, 2009). Its primary function is to transfer certain risks from clients, consultants, contractors, subcontractors and other parties involved in the construction project to insurers to provide contingent funding in time of difficulty. Construction insurance plays an increasingly important role in guaranteeing the success of projects, with insurers sharing losses resulting from natural disasters and other contingencies (Ashy B, 2014). However, insurance sometimes doesn't receive the attention it deserves because practitioners do not have a clear understanding of risk allocation and the strategy of risk management through insurance (Walewski, 2005) (Heidenhain, 2011).

There is a growing body of interests in construction insurance, supporting interactions between the construction industry and the insurance industry. However, it is not always clear why construction insurance exists and how it operates from the perspective of the construction industry. This paper argues that to provide a convincing explanation on this interaction, one need to improve the theoretical and analytic frameworks in four key areas: the nature of construction risks, risk transfer and insurance mechanism, insurable risks, and perspectives on risks from concerned parties.

\subsection{Objectives}

\subsubsection{General objective}

The general objective of this research was mainly alarms with creating awareness about the role of insurance companies for those involved the construction sector in Ethiopia.

\subsubsection{Specific objectives}

The specific objectives of the study were: -

* To assess the practice of insurance in Ethiopia construction industry.

* To examine the understanding of stakeholders involved in the construction industry towards being insured.

* Identify the problems \& challenges encountered while practicing the insurance policy for construction industries in Ethiopia.

* To create the awareness with the construction industry towards being insured.

\section{Research methodology}

According to Ethiopian Ministry of Urban Development and Construction the number of registered contractors for 2018 budget year is about 2937, likewise according to National Bank of Ethiopia there are 16 registered insurance companies so far. As a result, censes sampling was used for insurance companies, and a judgment sampling which is a type of nonrandom sampling based on the opinion of an expert was used for addressing contractors. After that data was analyzed and up on which the conclusions and recommendations were made.

\subsection{Questionnaire design}

The questionnaire survey was designed to assess the role of insurance companies in the construction industry in perception of the contractors. The questionnaire was based from literature review that was developed through the reference of different books, journals and internet sources. The questionnaire includes two categories, i.e. questionnaire for contractors and questionnaire for insurance companies separately which contains 23 and 18 questions respectively.

\section{Result analysis and discussion}

The questionnaires were presented with questions designed to identify the problem and challenge encountered while practicing construction insurance policy for construction industries, to create awareness within the construction industries, to examine the understanding of stakeholders involved in the construction industries towards being insured and to study the practice of insurance in the Ethiopian construction industries. Generally, 
assesses the role of insurance companies for Ethiopians construction industry while practicing construction insurance and to find out the impact of these problems, which is helpful to develop conclusion and recommendation on the problems encountered.

\subsection{Questionnaire response rate}

This research verifies the problems in implementing construction insurance such as high premium coverage, difficult to come up with similar cost estimation between Construction Company and the insurance company, misunderstanding between the insurance companies and the insured. These problems have been identified from the questionnaires' that have collected and discussed with the professionals of the contracting parties. Since the research mainly concerns the contractors and insurance, the questionnaires were distributed to 1500 contractors and 16 insurances and among them 1278 and 15 of the companies respectively have filled the questionnaire.

Table 1 Sample distribution and return rate of responses

\begin{tabular}{|l|l|l|l|l|}
\hline No. & $\begin{array}{l}\text { Stakeholders } \\
\text { (participants) }\end{array}$ & Distributed in numbers & $\begin{array}{l}\text { Returned in } \\
\text { number }\end{array}$ & $\begin{array}{l}\text { Returned in percentage } \\
(\%)\end{array}$ \\
\hline 1 & Contractors & 1500 & 1278 & $85.2 \%$ \\
\hline 2 & Insurance & 16 & 15 & $93.75 \%$ \\
\hline
\end{tabular}

\subsection{Awareness of construction insurance policies}

According to the result analysis as shown in table 2, in aggregate $87.21 \%$ of the respondents are willing to buy insurance coverage even if it is not precondition for contracting and tendering process. This is resulted from; the construction company believes insurance as an important way of transferring liability that could arise from the construction business at varies level because construction by nature is a highly risky business. On the other hand, the rest $12.79 \%$ of the respondents believe that insurance is additional cost for the company so they don't buy insurance coverage for their projects unless they are obliged to buy so. This is due to most of the contractors believe that having insurance coverage for their projects is not that much necessary.

Table 2 Awareness of Construction insurance policies

\begin{tabular}{|l|c|c|c|}
\hline \multirow{2}{*}{ Types of insurance policies } & \multicolumn{3}{|c|}{ Contractors respond } \\
\cline { 2 - 4 } & Yes & No & Percentage of contractors say yes \\
\hline Contractor's all risk (CAR) & 850 & 428 & $66.51 \%$ \\
\hline Material damage (MD) & 945 & 333 & $73.94 \%$ \\
\hline Third party insurances (TPI) & 1139 & 139 & $89.12 \%$ \\
\hline Labor insurance (LI) & 1215 & 63 & $95.07 \%$ \\
\hline Construction plant and machinery (CPM) & 1278 & 0 & $100 \%$ \\
\hline Machinery breakdown insurance (MBI) & 1260 & 18 & $98.59 \%$ \\
\hline
\end{tabular}

\subsection{Insurance coverage of construction projects}

Insurance is a way of transferring risk to insuring party in order to minimize risk and damages caused. In Ethiopia most of the construction projects are accident prone and in order to come over these risks most of the contractors questioned for this research have responded that they did not insure their projects in order to minimize the risks. From the collected data $87.48 \%$ of the projects under the contractors are not insured. Based on this data the most of the construction contractors are not insured which shows that the contractors are under risk.

Table 3 Insurance Coverage

\begin{tabular}{|l|l|l|l|}
\hline No & $\begin{array}{l}\text { Companies use insurance coverage for } \\
\text { project }\end{array}$ & $\begin{array}{l}\text { Companies doesn't use } \\
\text { insurance coverage for } \\
\text { project }\end{array}$ & $\begin{array}{l}\text { Percentage of insurance } \\
\text { coverage }\end{array}$ \\
\hline 1 & 160 & 1118 & $12.52 \%$ \\
\hline
\end{tabular}

\subsection{Practice of construction insurance by Ethiopian contractors}

Accordingly, the data collected indicated that most of contractors use Contraction plant and machinery, Contractors all risk and third party insurances policies in their construction projects. On the other hand, there is less insurance coverage for labors, material damages and machinery breakdown of the contractors. This implies that the contractors have a little knowhow of the use of insurance policies for labors, material damages and machinery breakdown and there is no any enforcement particularly for material damage, labor and third party insurance. 
Table 4 Percentage of practice of Construction insurance by Ethiopian Contractors

\begin{tabular}{|l|l|c|}
\hline No. & Types of insurance policy & Coverage percentages in percent \\
\hline 1 & Contractor's all risk (CAR) & 65 \\
\hline 2 & Material damage (MD) & 18 \\
\hline 3 & Third party insurances (TPI) & 55 \\
\hline 4 & Labor insurance (LI) & 35 \\
\hline 5 & Construction plant and machinery (CPM) & 90 \\
\hline 6 & Machinery breakdown insurance (MB) & 39 \\
\hline
\end{tabular}

\subsection{Insurance period implemented by contractors}

As shown in table 5, that almost all of the contractors implement every year renewable insurance period for those insured properties. This question has the intention of finding out weather the companies use insurance till the end of the project or only agree to satisfy the contract obligation.

As per the questionnaire most of the construction contractors use every year renewal policy, this is due to the cost of the premium they pay and the difference in expected risk encountered by the contractors.

Table 5 Insurance period

\begin{tabular}{|l|c|c|c|}
\hline Insurance period & $\begin{array}{l}\text { No of respondents for each types of } \\
\text { insurance period }\end{array}$ & $\begin{array}{l}\text { number of } \\
\text { users }\end{array}$ & $\begin{array}{l}\text { Percentage of } \\
\text { users }\end{array}$ \\
\hline Contract time & 1119 & 60 & $4.69 \%$ \\
\hline $\begin{array}{l}\text { Contract time including } \\
\text { extension time }\end{array}$ & 1278 & 0 & $00 \%$ \\
\hline Every year renewable & 1218 & 99 & $95.31 \%$ \\
\hline
\end{tabular}

\subsection{Claim rejection by insurance company}

When an accident occurs, the construction companies claim for replacement payment from the insurance companies. From $100 \%$ of the collected data from the respondents for this assessment shows that contractor claims have not been rejected by the insurer.

\subsection{Reasons of contractor to be insured}

According to the respondent response from the questionnaire as shown in figure 1, shows that the driving force for contractors to be insured were legal aspect (LA), new technology (NT), management consideration (MC), safety consideration (SC) and financial consideration(FC) respectively.

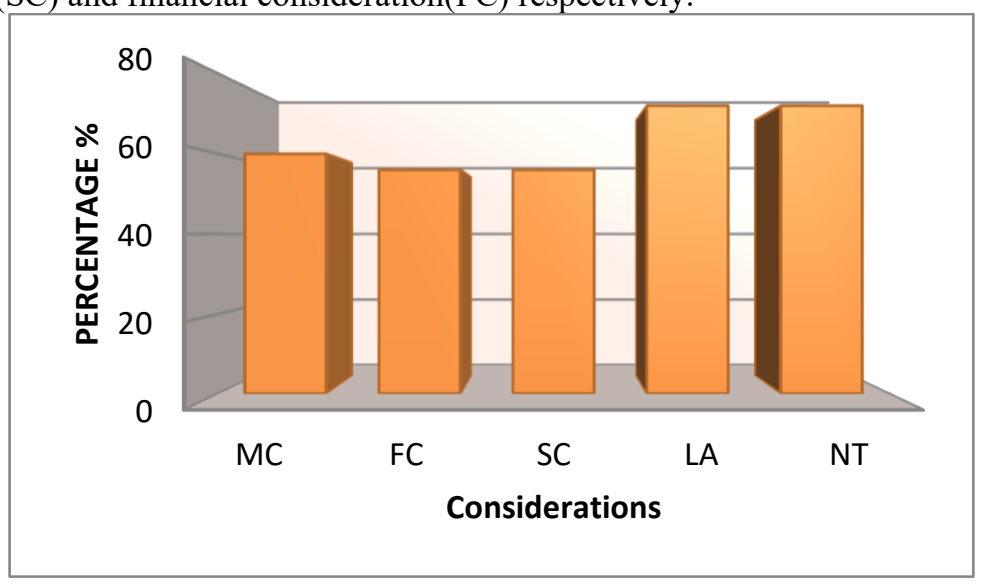

Figure 1. Reason of contractors for being insured

\subsection{Insurance policies practiced to contractors by insurer}

For each risks encountered in construction projects the insurance companies have specific policies in order to manage it accordingly. Each of these policies has their own general conditions and exclusions. Most of the respondents for this research have low awareness of these construction insurance policies in addition they know only specific type of the insurance policy which they are forced to use for contractual purposes. Considerable number of respondents has no insurance converges and number of contractors doesn't care to have it even though they have the knowhow and the contract obligation.

The data collected from the questionnaire shows that most of the insurance company provide insurance coverage for third party insurance, contractor's all risk insurance, contractor's plant and machinery insurance, machinery breakdown insurance and erection all risk insurance coverage respectively in descending order 
respectively as shown in figure 2 .

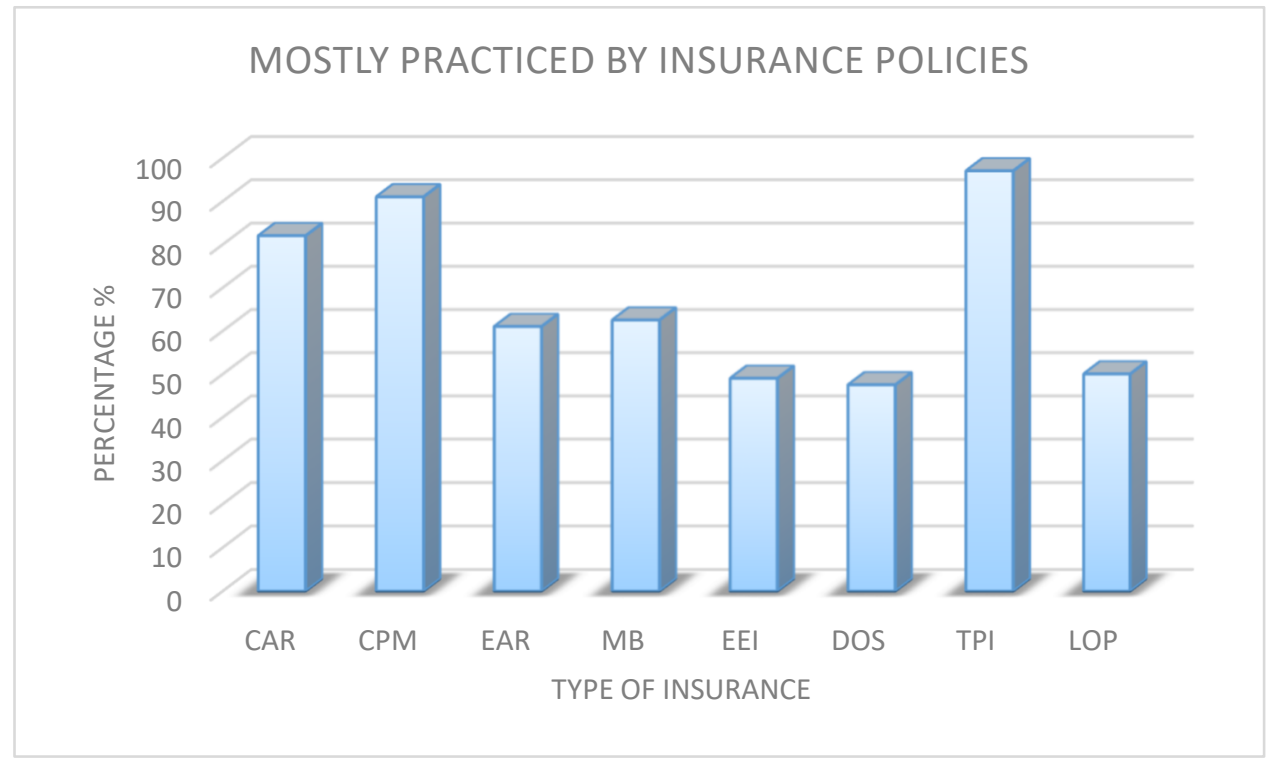

Figure 2 Insurance Policies Practiced to Contractors by insurer

\subsection{Major challenges of insurance companies in Ethiopia}

Generally, the data that collected by questionnaire from insurance companies are show that the main challenges of insurance companies related to engineering industries are insufficient documentation of customers, low level of awareness towards the benefit of insurance, finance capacity of insurance companies, price under cutting, luck of professionals and the absents of strong industries association.

\section{Conclusions and recommendation}

\subsection{Conclusion}

Insurance is risk transfer vehicle. It is a payment of premium in exchange for transferring a particular risk from parties to insurers. But most contractors who responded to this research listed the payment premium as cost disadvantage which come up to be a major challenge to use construction insurance in Ethiopia.

most construction projects contractors here in Ethiopia misunderstand the policy provisions they signed to buy and mostly their claims are rejected since it is in appropriate claim they raise and because of cost estimation problems raised between the client and the insurer in addition to that since insurance companies are conditional, contractors and other business firms must have to know the conditions and policies of the insurance firms.

This study found that misunderstanding and low awareness about the benefit to be insured as major problem to implement construction insurance by Ethiopian contractors. Addition to that the problems and challenges encountered in the Ethiopian construction industry for contractors were found that high premium payments, low awareness and misunderstanding of the insurance policies, rejection of claims by the insurer due to fallacy of policies and contract documents and problem of estimating the cost of the damage in good faith. Most of the construction firms doesn't use specific engineering insurance if they are not obliged by the construction contract document and have low awareness about it,

Generally, this research found that, in Ethiopia, the application and awareness of construction insurance is very low. Even if the law which forces the implementation of construction insurance in construction projects, written in PPA and FIDIC contract documents, which are highly used by the stakeholders of the construction industry here in regulatory parties did not enforce it.

\subsection{Recommendation}

Based on the findings of this research, the researcher would like to recommend the following points that should give emphasis in the improvement of construction insurance practiced in public works, considering the negative impact of insurance not being practiced in the construction industry of Ethiopia.

To overcome the problems related with knowledge and awareness about the construction insurance policies that should be practiced in the construction industry the government should develop trainings and awareness creation workshops, enforcing construction insurance in all construction projects and controlling mechanism to enforce the practice of insurance stated in the condition of contract.

The other challenge faced by the construction insurance users is that they may not be insured for the risk they 
require if the insurance company here in Ethiopia is not reinsured of that specific risk from an international reinsuring company. Due to this the government must provide public reinsurance company for local construction companies to satisfy their insurance need and establish a government agency to take responsibility and overlook the construction insurance practice in Ethiopia

Use the advance payment disbursement schedule for the proper usage of the advance payment to give guaranty bonds and monitor for the contractor to go ahead with estimated project completion time for minimizing problems related with improper usages of the advance payment by the contractors and delay on the project completion time.

\section{Bibliography}

Abebe D, F. G. (2007, julay). Impacts of remedial rights on construction contractures in Ethiopia.

Ashy B, D. K. (2014). Roles of insurance in construction and infrastracture project. Vol. 5, issue 12. IJCET.

Dereje, W. (2014). The role of financial institution in the growth of small and medium enterprises in Addis Ababa. Addis Ababa.

EPPA. (2011). Standard biding document for procurement of works, good and services for competative bidings. Addis Ababa.

FIDIC. (2009). Condtion of contract for construction of building and engineering works designed by the employer(Red Book).

Heidenhain, D. (2011). Managing technological risks: a challangr for proffesional engineering inssurans. Geneva papers on risk insurances-issue and practice.

Hicksone, R. (1987). Construction insurance management and c;aims. London: Witherby.

Melesse, M. (2006). The role of financial institutions for the Ethiopia's construction industry. Addis Ababa.

Palemer WJ, M. J. (1996). Construction insurance, bonding and risk management. NY: MeGraw hill proffesional.

Rahman MM, K. M. (2002). Risk managementin the construction industry; moving towardes joint risk management, engineerning construction and architectural management.

Randell EG, Y. D. (2003). Risk manager's insurance guide. Department of community and Economic development, hurrisburg.

Walewski, J. A. (2005). international project risk assessment. N.Y. 